http://dx.doi.org/10.30681/23588403v12i03104120

\title{
ANÁLISE DE ASPECTOS PROTOTÍPICOS E ENUNCIATIVOS PROJETADOS NA MATERIALIDADE DISCURSIVA DE UM POEMA
}

\author{
Rafael da Silva MOURA (UPF) ${ }^{1}$
}

Data de recebimento: $18 / 02 / 2018$

Aceite: 19/04/2018

\begin{abstract}
Resumo: Este artigo propõe um estudo ancorado em pressupostos da Linguística e da Literatura, com o objetivo de analisar aspectos prototípicos e marcas enunciativo-discursivas inscritas em um texto poético. A investigação se fundamenta, principalmente, em estudos desenvolvidos por Moisés (1970), D'Onofrio (2007), Soares (1993) e Goldstein (2006), no que diz respeito a princípios constitutivos de gênero poema, bem como em pressupostos conferidos por Saussure (2006) e Benveniste (1976; 2006), em relação aos conceitos de língua, linguagem, enunciação e subjetividade. Com base nesse arcabouço teórico, analisa-se o engendramento discursivo do soneto XIII, de Mario Quintana. A análise comprova que a aplicação de elementos de diferentes áreas do saber possibilita depositar um olhar mais profundo e sistemático a textos poéticos, haja vista que dá conta, simultaneamente, de aspectos prototípicos do gênero, bem como dos recursos linguístico-enunciativos manipulados na materialização discursiva, os quais corroboram para a construção da subjetividade do enunciador e interferem na constituição semântica do texto.
\end{abstract}

Palavras-chave: Soneto. Aspectos prototípicos. Enunciação. Sentidos subjacentes.

\begin{abstract}
This article proposes a study anchored in assumptions of Linguistics and Literature, with the objective of analyzing prototypical aspects and enunciative-discursive marks inscribed in a poetic text. The research is guided mainly by studies developed by D'Onofrio (2007), Soares (1993) and Goldstein (2006), in terms of constitutive principles of genre poem, as well as in assumptions conferred by Saussure (2006) and Benveniste (1976; 2006), in relation to the concepts of language, enunciation and subjectivity. Based on this theoretical framework, the discursive development of sonnet XIII, by Mario Quintana, is analyzed. The analysis proves that the application of elements from different areas of knowledge makes possible to place a deeper and more systematic look at poetics texts, because it allows to observe simultaneously prototypical aspects of the poetic genre, as well as the linguistic-enunciative resources manipulated in the discursive materialization, which contribute to the construction of the subjectivity of the enunciator and interfere in the semantic constitution of the text.
\end{abstract}

Keywords: Sonnet. Prototypic aspects. Enunciation. Underlying senses.

\footnotetext{
${ }^{1}$ Mestrando em Letras - Leitura e Formação do Leitor, pela Universidade de Passo Fundo. Passo Fundo, Brasil. E-mail: rafa1_moura@hotmail.com
} 


\section{Introdução}

A palavra texto soa familiar aos ouvidos de qualquer indivíduo, inserido ou não em ambiente escolar, uma vez que todas as atividades comunicativo-interativas do cotidiano se fundamentam em textos, verbais ou não-verbais. O texto literário, entretanto, confere um trato diferenciado à língua, articulando escolhas enunciativas enriquecidas, o que exige do sujeitoleitor um olhar também diferenciado e mais atento à materialização discursiva, para que seja possível a inferência de sentidos à teia de significações que subjazem a superfície textual.

Diante desse contexto, este artigo se debruça sobre o complexo processo de ressignificação textual, propondo o desenvolvimento de um estudo baseado em pressupostos da Linguística e da Literatura, com o objetivo de analisar marcas enunciativo-discursivas inscritas em um texto poético, as quais corroboram para a construção da subjetividade do enunciador e interferem na constituição semântica do texto. Articular áreas ao mesmo tempo tão próximas, uma vez que se relacionam ao uso da língua, mas com especificidades teóricas e metodológicas tão singulares, confere aspectos desafiadores a este estudo. Essa concepção interdisciplinar, porém, faz-se necessária, a fim de evidenciar a necessidade de se romper as fronteiras que separam diferentes campos do saber e, por conseguinte, sedimentam e enfraquecem a construção do conhecimento.

Isso posto, ressalta-se que esta investigação se caracteriza como bibliográfica, exploratório-descritiva, de natureza aplicada, com abordagem qualitativa, ancorando-se, principalmente, ao seguinte arcabouço teórico: Moisés (1970), D'Onofrio (2007), Soares (1993) e Goldstein (2006), Saussure (2006) e Benveniste (1976; 2006). Com base no referido quadro teórico, analisam-se os engendramentos discursivos projetados no Soneto XIII, do livro Antologia Poética, de Mario Quintana, enfocando em elementos prototípicos do gênero soneto, bem como nas marcas enunciativo-discursivas projetadas na superfície textual, a fim de se alcançar os sentidos subjacentes à materialidade linguística do referido texto.

A apresentação deste estudo segue o seguinte percurso: na primeira seção, além de tratar, brevemente, de uma concepção conceitual quanto à Literatura, também se discorre sobre o gênero poesia, ressaltando sua natureza prototípica e semântica; na seção seguinte, discutem-se os conceitos de língua e linguagem, enunciação e subjetividade, que são 


\section{Revista de Estudos Acadêmicos de Letras}

edificados na relação entre Homem, Língua e Sociedade; na sequência, após ser apresentado o percurso metodológico adotado, desenvolve-se a análise do poema supracitado; e, por fim, na última seção, são apresentadas algumas considerações gerais quanto ao desenvolvimento e aos resultados do estudo.

\section{O que a Literatura tem a dizer sobre as manifestações discursivas?}

A palavra "Literatura" é usada para se referir à "arte das belas letras", a arte da palavra (JOUVE, 2012). Entretanto, isso não faz com que qualquer texto, apenas por mobilizar o sistema gráfico da língua, possa ser considerado texto literário. A linguagem literária recebe um trato diferenciado, que a enriquece e a distingue da linguagem ordinária das relações sociocomunicativas diárias, projetando arranjos linguístico-semânticos singulares. Conforme Goldstein (2006, p. 5), "o texto literário adquire certo grau de tensão ou ambiguidade, produzindo mais de um sentido" ou, até mesmo, atribuindo valores semânticos diferentes do uso comum a determinado vocábulo.

A beleza e a riqueza semântica e vocabular da linguagem literária, porém, não são os únicos aspectos que apartam o literário do ordinário. Nas palavras de Jouve (2012), “é próprio da literatura [...] tentar satisfazer ao mesmo tempo uma expectativa estética e uma exigência intelectual" (p. 35). Nesse sentido, mesmo projetando a visão subjetiva do autor, a literatura possui um aspecto sócio-histórico, haja vista que carrega traços da história, da organização social e das ideologias de um determinado povo em uma determinada época. Logo, além de se configurar material de leitura requintado, o texto literário também confere uma profícua fonte de conhecimento e cultura ao leitor, conduzindo-o, virtualmente, por contextos sóciohistóricos que, talvez, não pudessem ser vivenciados pessoalmente por esse sujeito.

Além disso, a literatura possui a capacidade de desfamiliarizar o ordinário, de problematizar situações e concepções ideológicas que, de tão naturalizadas nas relações cotidianas, passam despercebidas pelos olhares dos sujeitos. A leitura de textos de natureza realmente literária, conforme Jouve (2012, p. 119), proporciona a "descoberta de uma dimensão de nós mesmos até então inexplorada, como do sentimento de sermos confrontados com uma questão fundamental".

O texto literário, por conseguinte, comporta em si mesmo características de universalização e de transcendência, não prendendo sua significação ao contexto inicial de produção. Ou seja, a temática nele abordada, independentemente de espaço geográfico e contexto histórico, é retextualizada no ato da leitura e, consecutivamente, em alguma medida, 


\section{Revista de Estudos Acadêmicos de Letras}

configura-se atual, provocando um deslocamento no leitor, que, ao ver o mundo pelo olhar do outro, talvez, identifique-se com essa nova visão e questione-se sobre a própria visão de mundo. Assim, a literatura também humaniza, transforma o Homem, uma vez que ela "nos permite aprender um pouco mais de nós mesmos" (JOUVE, 2012, p. 89) enquanto sujeitos, além revelar e problematizar convenções, normas e valores que perpassam as relações sociais.

Logo, fica claro que entender uma obra literária é um ato complexo. Então, a fim de organizar a relação entre os textos literários e os leitores, surge a necessidade de "reunir as obras literárias onde a realidade aparece de um determinado modo, através de mecanismos de estruturação [e significação] semelhantes" (SOARES, 1993, p. 7). Consecutivamente, concebe-se a denominação "gêneros literários", para se referir aos agrupamentos de textos literários de acordo com determinadas características neles inscritas. Pondera-se, assim, que os textos de um mesmo gênero literário projetam traços estruturais, semânticos e linguísticos, bem como funções comunicativo-interativas que, em alguma medida, assemelham-se.

O gênero, portanto, preexiste ao momento de produção textual, mas essa preexistência não significa um determinismo, em que, obrigatoriamente, um texto tem de se encaixar às características tidas como intrínsecas ao gênero pretendido, uma vez que "a aplicação mecânica de regras preestabelecidas nunca foi suficiente para gerar uma obra de arte" (JOUVE, 2012, p. 32). Entretanto, apesar de os gêneros literários não serem formas fixas e estanques, não é possível se distanciar demasiadamente das coerções postas pelo estilo próprio de cada gênero, sob pena de o texto perder a identidade ou mesmo a credibilidade. Isso justificaria a preocupação do escritor em escolher "um gênero, uma espécie e uma forma adequados à emoção, aos sentimentos e aos conceitos que pretende transmitir, pois cada uma daquelas categorias se presta para fins diferentes" (MOISÉS, 1970, p. 36). Ou seja, com vistas a tornar seu discurso inteligível, o sujeito-autor "dá-lhe a forma e a estrutura que lhe é congênita, enfim, enquadra-o num molde" (idem), corporificando-o em um determinado gênero, imprimindo ou não um estilo próprio.

Seguindo esse viés, ressalta-se que os textos do gênero Lírico, foco deste estudo, possuem sua origem instituída nos cantos líricos, sendo marcados pela emoção, pela musicalidade e pela minimização do distanciamento entre o "eu poético" e o objeto do discurso. Assim, ao passar para a forma escrita, mantiveram-se "recursos que aproximam música e palavra: as repetições de estrofes, de ritmos, de versos (refrão), de palavras, de sílabas, de fonemas, responsáveis não só pela criação das rimas, mas de todas as imagens que 
põem em tensão o som e o sentido das palavras" (SOARES, 1993, p. 24). O poema, nesse sentido, seria a forma atualizada/retextualizada dos cantos líricos da antiga Grécia.

Quanto a esse subgênero, Moisés (1970) lembra que quando se fala em poesia, de imediato se pensa em poema, e sempre que se refere a poema, subentende-se a poesia. Embora reconheça que essas concepções sejam imbricadas e, muitas vezes, vistas como sinônimos, o autor ressalta que o poema seria a concretude, aquilo que mais se aproxima de uma forma - apesar de não se resumir meramente a parte gráfica -, enquanto a poesia seria uma categoria abstrata, aquilo que ecoa do texto. Ou seja, as noções de poema e poesia estão inerentemente interligadas, estabelecendo uma majoritária relação de interdependência.

Moisés (1970) ainda assevera que o poema que recebe a inscrição da poesia pode ser composto sob dois modos: a) de modo descontínuo, em que é formado por linhas cortadas e ordenadas na vertical, em forma de colunas, e recebem o nome de versos, os quais são agrupados em estrofes; b) ou de modo contínuo, em que se visualizam linhas inteiramente ocupadas por palavras e, na maioria das vezes, não se faz um agrupamento, mas, sim, seguese o texto de maneira contínua, o qual é rotulado como poesia em prosa ou prosa poética.

Observa-se, porém, que, ao conceber a poesia como a forma mais elevada de manifestação da subjetividade e dos sentimentos, reconhece-se, também, que ela pode estar em tudo aquilo cuja beleza possa, em alguma medida, tocar os sujeitos de maneira extraordinária, estabelecendo um rompimento com o comum do cotidiano. Logo, mesmo em um texto publicitário, por exemplo, desde que o enunciador se manifeste por meio de uma linguagem mais enriquecida ou crie imagens por meio de um engendramento linguístico, seria possível sentir uma emanação poética de sua materialidade discursiva.

Assim, além de analisar cuidadosamente alguns aspectos constituintes do gênero poema, tais como elementos gráficos, fônicos e lexicais, a fim de se alcançar a subjacência semântico-discursiva do texto, faz-se necessária a análise desses elementos articulada a pressupostos de uma teoria que se debruce sobre a língua, principal mecanismo mobilizado na materialidade textual. Para tanto, na seção seguinte, são delineadas algumas considerações saussurianas sobre língua, bem como aspectos da teoria enunciativa benvenistiana, que se dedica ao estudo do processo de colocar o sistema linguístico em funcionamento.

\section{As relações humanas pela linguagem: alguns aspectos linguístico-enunciativos}


O homem, conforme Saussure (2006, p. 17), possui a habilidade de se apropriar de um sistema de signos e organizá-lo de forma a possibilitar a interação com seus semelhantes, habilidade essa denominada linguagem. Entretanto, "não está provado que a função da linguagem, tal como ela se manifesta quando falamos, seja inteiramente natural, isto é: que nosso aparelho vocal tenha sido feito para falar, assim como nossas pernas para andar". Por esse viés, o homem poderia ter utilizado qualquer outro aparelho para criar e manejar um sistema de signos, tal como construir imagens sensoriais por meio de gestos, a fim de proporcionar a interação, mas, talvez, por razões de facilidade ou de amplitude de modulação, serve-se do "aparelho vocal como instrumento da língua" (SAUSSURE, 2006, p. 17). Ou seja, não é a linguagem um elemento "natural ao homem, mas a faculdade de construir uma língua, vale dizer: um sistema de signos distintos correspondentes a ideias distintas" (idem, p. 18).

Além disso, a linguagem se constitui de dois aspectos que se completam: um individual, a fala, e outro social, a língua. Quanto à fala, Saussure (2006, p. 22) a caracteriza como um ato individual e a parte concreta da linguagem, além de ser modulada de acordo com a vontade dos sujeitos, recebendo, assim, marcas e traços de subjetividade. Isso reforça sua natureza heterogênea, portanto secundária. Por outro lado, a língua representa a parte social e psíquica da faculdade da linguagem, cuja essência é independente das vontades do indivíduo, e diz respeito a "um conjunto de convenções necessárias, adotadas pelo corpo social para permitir o exercício dessa faculdade nos indivíduos" (SAUSSURE, 2006, p. 17). Esse sistema de signos manifesta uma atividade simbólica, um conjunto de combinações utilizadas por determinado grupo social que permite a criação de conceitos que sirvam para categorizar, organizar e interpretar a realidade do mundo. Nesse sentido, a língua seria um

tesouro depositado pela prática da fala por todos os indivíduos pertencentes à mesma comunidade, um sistema gramatical que existe virtualmente em cada cérebro ou, mais exatamente, nos cérebros dum conjunto de indivíduos, pois a língua não esta completa em nenhum, e só na massa ela existe de modo completo. (SAUSSURE, 2006, p. 45).

Embora assuma a língua como objeto de estudo, Saussure (2006) enfatiza que ela não se realiza senão pela fala: no momento em que decide falar, o sujeito irá buscar no sistema linguístico as palavras das quais precisa para manifestar seu discurso, para corporificá-lo. Ou seja, "a língua é necessária para que a fala seja inteligível e produza todos os seus efeitos; mas esta é necessária para que a língua se estabeleça” (SAUSSURE, 2006, p. 27). 


\section{Revista de Estudos Acadêmicos de Letras}

A partir dos pressupostos delineados pelo mestre genebrino, Benveniste (1976, 2006), por sua vez, debruça-se sobre o fenômeno linguístico considerando a língua em funcionamento, dando fundamental atenção à posição do homem enquanto sujeito que se apropria de um sistema de signos, neste caso, a língua, para estabelecer uma relação comunicativo-interativa com seus semelhantes, e aos fenômenos relacionados a esse processo. Instaura-se, por conseguinte, a concepção de enunciação, que é concebida como "este colocar em funcionamento a língua por um ato individual de utilização".

A enunciação, porém, não deve ser confundida com o produto final desse processo - o texto -, posto que "é o ato mesmo de produzir um enunciado, e não o texto do enunciado, que é o nosso objeto. Este ato é o fato do locutor que mobiliza a língua por sua conta" (BENVENISTE, 2006, p. 82). A língua, então, possui a propriedade de conferir ao sujeito a capacidade de nomear o mundo e de exteriorizar um mundo interior, por isso "não atingimos nunca o homem separado da linguagem e não o vemos nunca inventando-a" (BENVENISTE, 1979, p. 285). Mas, antes de ser acionada pelos usuários, ela nada mais é do que uma possibilidade, um sistema abstrato de signos linguísticos à disposição dos falantes.

Apesar de a língua configurar-se nesse elo entre o homem e o mundo, Benveniste (2006) refuta a ideia de considerá-la um mero instrumento dos sujeitos em suas relações comunicativo-interativas diárias. Pelo contrário: embora seja algo criado e estabelecido por uma convenção social, a língua é interna ao ser humano, portanto psíquica e fisiológica, e não pode ser comparada a um instrumento, que seria externo e material. Ainda, reforçando o caráter primordial da língua, Benveniste (2006, p. 63) ressalta que é apenas ela que "torna possível a sociedade", uma vez que "constitui o que mantém juntos os homens, o fundamento de todas as relações que por seu turno fundamentam a sociedade".

Mesmo sendo uma ação individual do sujeito, a enunciação é calcada na relação discursiva que este exerce com um parceiro, real ou idealizado, ou seja, não haveria motivo para se enunciar, para se manifestar linguisticamente, sem ter o objetivo de interagir com um outro, com vistas a produzir uma ação, uma resposta, uma adesão, um posicionamento etc. Logo, "não atingimos jamais o homem reduzido a si mesmo e procurando conceber a existência do outro. É um homem falando que encontramos no mundo, um homem falando com outro homem" (BENVENISTE, 1979, p. 285).

Nesse processo dialógico, então, o sujeito apropria-se do aparelho formal da língua, e das possibilidades semânticas por ele proporcionadas, e enuncia-se, projetando o seu dizer na instância discursiva. Tem-se, por conseguinte, uma situação enunciativa, em que aquele que 
toma a palavra é designado por "eu”, direcionando seu discurso, explicita ou implicitamente, a um "tu", seu interlocutor. Há, entretanto, uma propriedade de inversibilidade entre esses sujeitos do discurso, em que, quando o "tu" toma para si o curso da palavra, ele acaba por configura-se em um "eu", e o "eu” anterior passa a ser o "tu”. Essas duas categorias de pessoa - "eu" e "tu" - manifestam uma oposição semântico-discursiva a um "ele", considerado a não-pessoa do discurso, por ser apenas o objeto do dizer ou todo aquele que não participa do circuito de troca dialogal, que não se manifesta neste (BENVENISTE, 1979; 2006).

Nessa dinâmica de personalidade entre "eu" e "tu", estabelece-se a subjetividade e a correlação desta com os sujeitos, uma vez que o poder de discursivização da língua pertence unicamente ao "eu", que seria a pessoa subjetiva, enquanto "tu" se configura a pessoa não subjetiva. Quanto a isso, Benveniste (1979, p. 286) assevera que "a consciência de si só é possível se experimentada por contraste" e que "a linguagem só é possível porque cada locutor se apresenta como sujeito, remetendo a ele mesmo como eu do discurso". Sem enunciar-se, o homem deixa de participar ativamente de atividades sociais pela linguagem, pois, não corporificando seu discurso, passa a assumir a posição da não-pessoa, aquela que é passiva, um objeto no universo discursivo. Assim sendo, “é na linguagem e pela linguagem que o homem se constitui sujeito" (BENVENISTE, 1979, p. 286).

A subjetividade, conforme Benveniste (1979), é capacidade do locutor se apropriar do sistema linguístico e propor-se como sujeito de seu dizer, um sujeito discursivo, que se projeta no discurso e nele deixa marcas de pessoalidade. Ou seja, o enunciador manifesta seu "ego", dizendo "eu", com vistas a atingir um "eco", que seria o "tu”. Além dos pronomes revelados na primeira pessoa, outra marca de subjetividade na linguagem são os indicadores da deixis: “demonstrativos, advérbios, adjetivos, que organizam as relações espaciais e temporais em torno do 'sujeito' tomado como ponto de referência: 'isto, aqui, agora' e as suas numerosas correlações ‘isso, ontem, no ano passado, amanhã', etc.” (BENVENISTE, 1979, p. 288).

O sujeito, assim sendo, marca-se na linguagem por meio da subjetividade ao instaurarse no discurso por um "eu", inserido no espaço do "aqui" e no tempo do "agora", que são reconhecidos pelo alocutário ao entrar em contato com o enunciado. E esse projeto enunciativo desenvolvido pelo sujeito visa a reproduzir a realidade de acordo com seu olhar individual e projetá-la ao seu interlocutor, por meio da linguagem. Assim, "aquele que fala faz renascer pelo seu discurso o acontecimento e a sua experiência do acontecimento. Aquele que o ouve apreende primeiro o discurso e através desse discurso, o acontecimento reproduzido". (BENVENISTE, 1976, p. 26). Diante disso, a fim de desvendar o processo de 


\section{Revista de Estudos Acadêmicos de Letras}

ressignificação que envolve a interação dos sujeitos com um material discursivo e delinear um percurso interpretativo para isso, na próxima seção desenvolve-se uma análise de um poema.

\section{Desvendando os sentidos projetados pelas marcas enunciativas inscritas no poema}

Nesta seção, com base nos preceitos teóricos abordados anteriormente, desenvolve-se um estudo do Soneto XIII, do livro Antologia Poética, de Mario Quintana, enfocando em elementos prototípicos do gênero, bem como nas marcas enunciativo-discursivas projetadas na superfície textual, a fim de se alcançar os sentidos subjacentes à materialidade linguística do referido poema. Para tanto, a análise vem assim organizada: primeiramente, a partir da análise de elementos gráficos, fônicos e lexicais, evidenciam-se as estratégias enunciativas relacionadas ao subgênero poema. Num segundo momento, abordam-se os traços semânticos que corroboram tanto para a articulação entre os sujeitos da interação comunicativa ("eu" e "tu"), como para a projeção da subjetividade do enunciador na materialidade discursiva, que se articulam e fundamentam a semântica global do poema.

Segue a transcrição do poema a ser analisado, retirada de Quintana (1997, p. 19).

\section{XIII}

Da vez primeira em que me assassinaram

Perdi um jeito de sorrir que eu tinha...

Depois, de cada vez que me mataram,

Foram levando qualquer coisa minha...

Hoje, dos meus cadáveres, eu sou

O mais desnudo, o que não tem mais nada...

Arde um toco de vela, amarelada...

Como único bem que me ficou!

Vinde, corvos, chacais, ladrões de estrada!

Ah! Desta mão avaramente adunca,

Ninguém há de arrancar-me a luz sagrada!

Aves da Noite! Asas do Horror! Voejai!

Que a luz, trêmula e triste como um ai,

A luz do um morto não se apaga nunca!

Embora o texto poético tenha uma unidade semântica articulada por características próprias a esse gênero, "ao analisar um poema, é possível isolar alguns de seus aspectos, num procedimento didático, artificial e provisório" (GOLDSTEIN, 2006, p. 5). Também, para 


\section{Revista de Estudos Acadêmicos de Letras}

melhor organizar e desenvolver esse processo analítico "é mais simples começar pelos aspectos mais palpáveis do poema, aqueles que saltam aos olhos - ou aos ouvidos" (GOLDSTEIN, 2006, p. 6). Logo, conforme D’Onofre (2007, p. 184), “o primeiro contato que temos com o poema escrito é o ótico, pois, pela sua configuração gráfica apresenta-se como uma feição plástica”. Observa-se, então, que o poema analisado apresenta certa simetria na organização de sua forma: são 14 versos, distribuídos em quatro estrofes, sendo as duas primeiras constituídas por quatro versos e as duas últimas por três. Tal estruturação evidencia que esse poema pode ser considerado um soneto, cujo nome, de acordo com Soares (1993), originou-se do italiano sonetto, que se relaciona com son (melodia, canção), e nomeia "todo poema de catorze versos, dispostos em dois quartetos e dois tercetos" (p. 35).

Os esquemas de rima inscritos em sonetos eram constituídos, originalmente, da seguinte forma: $\mathrm{ABAB}, \mathrm{ABAB}, \mathrm{CCD}, \mathrm{CCD}$ ou $\mathrm{ABAB}, \mathrm{ABAB}, \mathrm{CDC}$, DCD (SOARES, 1993). Mas essa esquematização fixa foi assumida por diferentes poetas, recebendo, por conseguinte, variações estilísticas que se remodelaram com o passar do tempo, como se observa na configuração atribuída por Quintana (1997) ao soneto XIII, que se afasta em demasia do padrão original, seguindo um esquema diferenciado, a saber: ABAB, CDDC, DED, FFE. Esse pequeno detalhe esquemático já proporciona uma amostra do caráter transgressor e questionador de Quintana, que, embora se aproxime de padrões canônicos, recusa-se a limitar-se a estes, imprimindo, então, sua individualidade em seus escritos.

A partir dessa constatação, chega-se ao nível fônico do poema, que é outro importante componente a ser analisado em textos poéticos, normalmente constituído por rimas, que conferem tanto ritmo como musicalidade ao texto. Goldstein (2006, p. 44) define rima como o nome dado à repetição de sons que guardam traços gráficos e, consequentemente, sonoros semelhantes, "ora no final de versos diferentes, ora no interior do mesmo verso, ora em posições variadas, criando um parentesco fônico entre palavras presentes em dois ou mais versos". A fim de proporcionar uma visão mais organizada da esquematização das rimas inscritas no soneto em análise, elas são apresentas a seguir de maneira agrupada:

Rimas A: "assassinaram" e "mataram";

Rimas B: "tinha" e "minha";

Rimas C: "sou" e "ficou";

Rimas D: "nada" e "amarelada"; "estrada" e "sagrada";

Rimas E: "adunca" e "nunca";

Rimas F: "voejai" e "ai". 
A partir do proposto por Goldstein (2006) e D’Onofrio (2007), também é possível identificar certa simetria na distribuição das rimas ao longo do poema: a) as rimas $\mathbf{A}$ e $\mathbf{B}$, por seguirem a sequência $A B A B$, são admitidas como alternadas ou cruzadas, uma vez que há um revezamento na sua inscrição no poema; b) as rimas $\mathbf{C}$ e as $\mathbf{E}$ são vistas como interpoladas, pois há outras rimas inscritas entre elas, deixando-as, de certa forma, um pouco afastadas; c) as rimas D seguem duas formas distintas de configuração, já que em "nada" e "amarelada" elas são emparelhadas, ou seja, aparecem em versos sequenciados, enquanto em "estrada" e "sagrada" são interpoladas, tendo outro verso entre elas; d) a rimas F, por fim, também são concebidas como emparelhadas, não havendo inscrição de outros versos entre elas.

As rimas, ainda, podem ser conceituadas como ricas ou pobres: "a rima pobre ocorre entre palavras pertencentes à mesma classe gramatical (dois substantivos, dois adjetivos, dois verbos etc.). E a rima rica se dá entre termos pertencentes a diferentes categorias gramaticais" (GOLDSTEIN, 2006, p. 48). Nesse viés, as rimas A e C são delineadas como pobres, pois as palavras que as compõem são elementos de uma mesma classe gramatical, ou seja, são verbos ("assassinaram" e "mataram"; "sou" e "ficou”). As demais rimas, por outro lado, são concebidas como ricas, sendo formadas por palavras de categorias gramaticais distintas, quais sejam: rimas B - verbo ("tinha") e pronome ("minha"); rimas D - advérbio ("nada") e adjetivo ("amarelada"), substantivo ("estrada") e adjetivo ("sagrada"); rimas E - adjetivo ("adunca") e advérbio ("nunca"); e rimas $\mathbf{F}$ - verbo ("voejai") e interjeição transformada em substantivo pela inscrição do artigo "um" ("um ai").

Os aspectos estruturais-estilísticos supracitados podem até parecer estanques e pouco contributivos na constituição semântica do poema, mas não se pode desprezar o fato de todo esse material ser resultado de um projeto enunciativo delineado pelo enunciador/autor, configurando-se produto de um ato intencional carregado de sentidos. Conforme Benveniste (1989, p. 86), “desde o momento em que o enunciador se serve da língua para influenciar de algum modo o comportamento do alocutário, ele dispõe para este fim de um aparelho de funções", fazendo determinadas escolhas, a fim de criar determinados efeitos de sentido.

Assim, toda essa estruturação cuidadosa do poema em forma de soneto e sua organização sonora em rimas simétricas, arranjadas de forma padronizada e enriquecida pela escolha vocabular, corporificam a atenção estética concedida pelo autor ao seu material discursivo. Quanto a isso, Jouve (2012, p. 17) refere que o primeiro contato que o leitor faz com o texto e que pode ser decisivo em relação ao prosseguimento da leitura diz respeito ao olhar estético depositado sobre uma obra. Logo, ao seguir esse rigor estilístico, além de 


\section{Revista de Estudos Acadêmicos de Letras}

“filiar-se à poesia e, portanto, à literatura e à arte", o poema XIII projeta a possibilidade de ser idealizado pelo leitor como um material de valor elevado, que recebeu um trato diferenciado, e, em tese, ofereceria uma leitura mais profunda e enriquecedora, merecendo, assim, ser lido.

Transpondo o olhar analítico para um liame mais profundo, os aspectos semânticos, cumpre ressaltar que, nas palavras de Moisés (1970), os textos de natureza poética, como é o caso do soneto em análise, têm por objeto um "eu", que manifesta uma concepção de mundo por meio de um olhar único, partindo de reflexões subjetivas do enunciador/autor. Assim sendo, seguindo as proposições benvenistianas, reconhece-se que "o ato individual de apropriação da língua introduz aquele que fala em sua fala", e isso, assim como na poesia, "é um dado constitutivo da enunciação" (BENVENISTE, 2006, p. 84).

É possível observar, nesse sentido, algumas marcas que evidenciam a inserção do enunciador no discurso inscrito no soneto XIII, a saber: a) o pronome objeto "me", inscrito nos primeiro, terceiro, oitavo e décimo primeiro versos, e o pronomes possessivos "minha", no quarto verso, e "meus", no quinto; b) e o pronome da primeira pessoa do singular, "eu", bem como verbos relacionados a essa pessoa do discurso - "perdi", "sou”. A inscrição desses vocábulos relacionados à primeira pessoa deixa transparecer a presença do enunciador enquanto sujeito de seu dizer, revelando algumas "formas específicas cuja função é de colocar o locutor em relação constante e necessária com a enunciação” (ibidem). Assim, apresentando marcas de pessoalidade, o enunciado revela também traços de subjetividade.

O "eu" lírico, ou o "eu" enunciativo, assim sendo, apropria-se virtualmente da língua e manifesta o seu discurso no mundo por meio de um engendramento discursivo subjetivo. Ao declarar-se locutor, esse sujeito discursivo "implanta o outro diante de si, qualquer que seja o grau de presença que ele atribua a este outro", posto que, "toda enunciação é, explicita ou implicitamente, uma alocução, ela postula um alocutário" (BENVENISTE, 2006, p. 84). Instaura-se, então, uma relação propriamente enunciativa, em que um "eu" se dirige a um "tu”. Considerando que, no poema em análise, o "eu” enunciativo é revelado pelo "eu” lírico, corporificado pelo autor, Mario Quintana, reconhece-se a inserção de três possíveis "tu":

a) o primeiro seria o próprio autor, uma vez que o "eu" pode estar "à procura da própria imagem, refletida na superfície do mundo físico" (MOISÉS, 1970, p. 46), ou seja, o poeta estaria articulando um discurso reflexivo sobre a própria existência, portanto, dirigindose a si mesmo.

b) o segundo "tu" seriam os opressores do "eu" lírico, aqueles que, aos poucos, vão destituindo este de sua própria essência, como se pode observar no verso "Vinde, corvos, 


\section{Revista de Estudos Acadêmicos de Letras}

chacais, ladrões de estrada!", em que o enunciador, ao inscrever a forma imperativa do verbo "vir" ("vinde"), dirige-se diretamente a alguém.

c) o terceiro "tu" seria o leitor, que é quem opera sobre o texto, mobilizando seus conhecimentos prévios (enciclopédicos, linguísticos), a fim de inferir os sentidos inscritos na profundidade textual. A perspectiva de reversibilidade e de continuidade de um diálogo, mesmo que virtual, projetada neste caso, manifesta-se na possibilidade de agenciamento do leitor diante do discurso que emana do texto, o que estabelece uma relação intersubjetiva entre “eu"/autor/enunciador e "tu”/leitor/enunciatário.

Observa-se, também, a referência a não-pessoa. Isto é, além de todo o conteúdo temático abordado no poema poder, de certo modo, configurar-se um "ele", na primeira estrofe, o "eu" direciona seu discurso a um "tu" referindo-se a um "eles", como se evidencia nos seguintes versos: "Da vez primeira em que [eles] me assassinaram", "Depois, de cada vez que [eles] me mataram". O pronome na terceira pessoa do plural, "eles", mesmo que implicitamente, é usado para se referir a sujeitos que, embora exerçam alguma ação sobre o enunciador - "me assassinaram", "me mataram" -, não participam da troca dialogal intersubjetiva exercida entre o "eu" e o "tu" discursivos, por isso são o objeto do dizer.

Outro elemento constituinte do texto literário que, de acordo com D’onofrio (2007), merece atenção no processo analítico são as escolhas lexicais e o valor semântico por elas conferido. Entretanto, cumpre ressaltar que "nunca se pode perder de vista a unidade do texto a ser recuperada no momento da interpretação, quando o poema terá sua unidade orgânica restabelecida" (GOLDSTEIN, 2006, p. 5). Ao examinar as escolhas lexicais, portanto, faz-se, aqui, uma leitura da implicatura destas na constituição da significação global do poema XIII.

Já de início, identifica-se a inscrição de palavras com carga semântica forte, que conferem um tom de obscuridade ao texto, tais como: "assassinaram", "mataram", “cadáveres”, “corvos”, “Aves da Noite”, “Asas do Horror”, “morto”. Essas palavras reforçam o olhar negativo que o enunciador deposita sobre a sociedade, mas não podem ser concebidas em seus sentidos literais, e, sim, quanto aos seus aspectos simbólicos, metafóricos. Quanto à concepção de metáforas, pode-se dizer que "seu mecanismo básico é constituído pela associação num sintagma de dois significantes apresentados como semelhantes, a que correspondem, contrariamente, significados diferentes" (D'ONOFRIO, 2007, p. 213).

A partir dessa proposição e considerando que "o soneto costuma conter uma reflexão ligada à vida humana" (GOLDSTEIN, 2006, p. 57), nota-se que o enunciador utiliza-se das escolhas e articulações vocabulares para projetar uma esfera introspectiva ao poema. Já no 
primeiro verso -"Da vez primeira que me assassinaram"-, deixa-se transparecer que o "eu" lírico fora "assassinado" mais de uma vez, concepção essa que recebe reforço semântico do terceiro verso -“Depois, de cada vez que me mataram"-, no qual se evidencia que essa ação opressiva se manteve como um ato frequente por um período indeterminado de tempo.

Os verbos "assassinar" e "matar", entretanto, recebem um valor metafórico, posto que não se referem a uma morte física, mas, sim, simbólica, podendo representar a opressão que o social exerce sobre esse sujeito, forçando-o, talvez, a adaptar-se a padrões sociais e a deixar de expressar sua individualidade, seu olhar subjetivo quanto ao mundo que o cerca. Essa noção de perda ou apagamento da identidade do "eu" lírico perante a sociedade fica ainda mais nítida nos segundo e terceiro versos -“Perdi um jeito de sorrir que eu tinha...", "Foram levando qualquer coisa minha..."-, sendo que essa perda não é concebida como um acontecimento natural do sujeito, mas, sim, como resultado da ação de um "outro" ser discursivo externo ao dizer.

Enquanto a primeira estrofe se refere a aspectos do passado -“assassinaram”, "perdi”, "mataram"-, a segunda propõe uma transposição para o presente, sendo marcada, explicitamente, pela inscrição do advérbio "Hoje" e de verbos conjugados no presente do indicativo -"sou", "tem”. Nessa estrofe, o "eu” lírico reflete quanto à sua condição atual, que, resultante de um processo de apagamento, ficou praticamente vazia da subjetividade desse sujeito - “O mais desnudo, o que não tem mais nada...”. Essa constatação é corroborada pelo fato de o "eu" lírico se apresentar como um "cadáver", que, figurativamente, pode ser concebido como algo que deixou de existir ou tornou-se obsoleto.

Por outro lado, o enunciador revela, nos terceiro e quarto versos dessa estrofe, que ainda lhe restou um toco de vela -“Arde um toco de vela, amarelada...", "Como único bem que me ficou!". A vela assume um caráter simbólico, podendo representar tanto certa pureza de espírito, como a clareza de uma "mente que se abre para penetrar no inconsciente e o fertilizar" (DICIONÁRIO, 2017), e, por ser caracterizada como amarelada, ela permite inferir uma ideia de velhice. Ou seja, o "toco de vela, amarelada...", assim como a inscrição constante de reticências na materialidade do poema, possibilitam o reconhecimento de marcas da passagem do tempo, manifestando o envelhecimento do "eu" lírico, e a permanência de poucos traços da consciência individual desse sujeito. Nos tercetos, porém, o "eu" lírico começa a manifestar certa reação diante desse contexto opressor:

a) inicialmente, observa-se a inscrição do verbo "vir" no modo imperativo, constituindo um vocativo, que convoca aqueles que deveriam, em tese, consumir os restos 
mortais do "eu" lírico, que deveriam findar com o que ainda lhe restara de subjetividade, de identidade -"Vinde, corvos, chacais, ladrões de estrada!";

b) na sequência, porém, o "eu" lírico ressalta que não permanecerá passivo diante da ação de seus opressores, e que, como um sovina que se agarra fortemente aos seus bens, ele não permitirá que corrompam a luz que lhe restou -“Ah! Desta mão avaramente adunca”, "Ninguém há de arrancar-me a luz sagrada!". Essa "luz", considerando que o "eu” lírico se corporifica no autor, pode ser concebida com a própria poesia, que habita o interior de Mario Quintana, e, por meio da expressão pela palavra, dá-lhe forças para enfrentar a opressão e as mazelas da vida;

c) por fim, fica ainda mais nítida essa ideia de enfrentamento, posto que o enunciador ordena, por meio do emprego do imperativo -"Voejai" -, que aqueles que lhe cercam e conferem valor negativo à sua vida se afastem -“Aves da Noite! Asas do Horror! Voejai!”-, pois, embora fraca, a luz que o sustenta não será apagada tão facilmente. Ou seja, o "eu" impresso do poema se manifesta, após tanto sofrer opressões, ainda inabalado, independentemente de sua miséria, mantendo-se firme perante as afrontas externas. Mas essa firmeza, vale ressaltar, foi construída juntamente com a maturidade do "eu” lírico.

Cumpre dizer, enfim, que o poema se articula com vistas a exprimir o sentimento do enunciador (a dor, a insatisfação, a tristeza) frente a uma ação externa involuntária aos seus desejos, e talvez, a partir disso, conduzir o leitor/enunciatário a refletir um pouco mais sobre si mesmo e sua relação com o mundo. Mas essa emoção inscrita no poema, em contrapartida, "não é aquela que o texto denota ou exprime, mas aquela que produz no leitor. Portanto, ela depende menos do texto do que daquele que o lê" (JOUVE, 2012, p. 101).

É nesse sentido que se observa que um mesmo texto pode significar de maneiras distintas dependendo do olhar lançado pelo leitor sobre ele. Isso, todavia, não significa que o texto está aberto a qualquer significação: ao materializar seu discurso, o enunciador desenvolve um projeto enunciativo, visando a transmitir algo ao seu enunciatário, e, para tornar o seu discurso inteligível, deixa marcas enunciativo-pragmáticas no texto, a fim de conduzir o processo de inferência de sentidos. Ou seja, há sentidos que mais se aproximam da finalidade discursiva proposta pelo enunciador, e alcançá-la depende muito da habilidade leitora do sujeito que com ela interage, bem como do conhecimento compartilhado entre os sujeitos da troca linguageira - "eu"/enunciador e "tu"/leitor.

\section{Considerações finais}


A partir das discussões aqui desenvolvidas, ficou evidente que a interação humana é feita pela representação, sendo, na maioria das vezes, a partir de textos falados e escritos, construídos pelo uso de signos linguísticos, que são uma forma de apreender a realidade, a qual só existe para os homens quando for nomeada. Nesse processo enunciativo, o enunciador se apropria virtualmente da língua e, normalmente, inscreve-se no discurso, deixando vestígios, marcas enunciativas do próprio dizer na materialidade discursiva, as quais devem ser reconhecidas e ressignificadas pelo leitor, pois projetam determinados efeitos de sentido.

O processo de ressignificação textual, entretanto, é complexo e desafiador, envolvendo aspectos pragmáticos e cognitivos. Além disso, embora o ato de ler, assim como a interação com textos, seja intrínseco às relações sociocomunicativas, ninguém nasce leitor. A habilidade leitora, por esse viés, tanto não é privilégio de poucos indivíduos que tenham nascido com um dom específico para isso, como tampouco é alcançada unicamente por meio de inúmeras e cansativas leituras. Essa habilidade, portanto, deve ser desenvolvida, uma vez que a compreensão está associada à observação de traços projetados na materialidade textual e a conhecimentos específicos a serem mobilizados no processo de inferência.

Diante desse contexto, o estudo articulou-se em torno do complexo processo de ressignificação textual, buscando subsídios em pressupostos da Linguística e da Literatura, com o objetivo de analisar marcas enunciativo-discursivas inscritas em um texto poético, as quais interferem na constituição semântica do texto. O cunho interdisciplinar inscrito no estudo, certamente, possibilitou depositar um olhar ao mesmo tempo mais amplo e mais profundo ao texto literário analisado, o qual requer um olhar mais atento e sistemático no processo de leitura, uma vez que confere um trato enriquecido aos recursos linguísticos manipulados na materialização discursiva.

Ressalta-se, por fim, que a análise aqui desenvolvida, além de não explorar toda a riqueza semântica projetada no corpus analisado - Soneto XIII, de Mario Quintana -, esboça apenas algumas (e não a única) possibilidades de exploração dos sentidos inscritos no texto poético. Espera-se, nesse contexto, que este trabalho também possa contribuir, em alguma medida, para qualificar a prática pedagógica de ensino da língua materna, levando a desenvolver estratégias que formem um leitor competente, que vai além da superfície textual e encontra os sentidos subjacentes. 


\section{REFERÊNCIAS}

BENVENISTE, Emile. Problemas de Linguística Geral. São Paulo: Companhia Editora Nacional, Editora da Universidade de São Paulo, 1976.

Problemas de Linguística Geral II. SP: Pontes, 2006.

DICIONÁRIO de símbolos. Disponível em: https://www.dicionariodesimbolos.com.br/vela/. Acesso em: 02 ago. 2017.

D'ONOFRIO, Salvatore. Forma e sentido do texto literário. São Paulo: Ática, 2007.

GOLDSTEIN, Norma Seltzer. Versos, sons, ritmos. 14. ed. São Paulo: Ática, 2006.

JOUVE, Vincent. Por que estudar literatura? São Paulo: Parábola, 2012.

MOISÉS, Massaud. A criação literária: introdução à problemática da literatura. 3. ed. São Paulo: Melhoramentos, 1970.

QUINTANA, Mário. Antologia poética. Porto Alegre: L\&PM Pocket, 1997.

SAUSSURE, Ferdinand de. Curso de linguística geral. São Paulo: Cultrix, 2006.

SOARES, Angélica. Gêneros literários. 3.ed. São Paulo: Ática, 1993. 